\title{
Device Contamination with Chemical or Other Material
}

National Cancer Institute

\section{Source}

National Cancer Institute. Device Contamination with Chemical or Other Material. NCI Thesaurus. Code C63133.

Problem associated with contamination of a device with a chemical substance or other non biologic material. 